\title{
The Participating Role and Path Analysis of Environmental NGO in Decision-making Process of Pollution-related NIMBY Facilities
}

\author{
Xinying Liu \\ Southwest Jiao Tong University, Chengdu, Sichuan, China \\ 2578531757@qq.com
}

Keywords: Environmental NGO; NIMBY Facilities; Decision-making; Participation

\begin{abstract}
With the rise of anti-burning and anti-PX movement, we are more concerned about NIMBY conflicts. Since NGOs are playing a more and more important role in relieving the conflicts, the paper put more emphasis on the participating role and path of environmental NGOs in decision-making process of pollution-related NIMBY facilities. Based on the research results of environmental NGO's participating in the decision-making of pollution-related NIMBY facilities, the paper analyzes the necessity of environmental NGO's participation in the decision-making of pollution-related NIMBY facilities, focusing on the practical cases, and summarizes the three aspects of environmental NGO's functions in the decision-making of pollution-related NIMBY facilities, including advocating of environmental protection, safeguarding public rights and promoting public decision-making. It is worth mentioning that this paper establishes the universal model of the participation stages of environmental NGOs in the decision-making of pollution-related facilities, analyzes the path and role of environmental NGOs in the start-up stage, multi-programing stage, decision-making stage, and implementation stage in the decision-making of pollution-related facilities, and provide ideas and methods for environmental NGOs' involving in such participation in the real life.
\end{abstract}

\section{Introduction}

With the development of urban and urbanization speed, the construction of public facilities is in full swing. However, not all public facilities are harmless, and NIMBY facilities are unavoidable. NIMBY (Not In My Back Yard), means "Do not build in my backyard" facilities[1]. NIMBY facilities have two characteristics: first, negative externalities, refers to the location and construction of the NIMBY facilities have a negative impact on the surrounding residents, so that the interests of the surrounding residents are damaged; second, inequality of the distribution of the cost and benefits, that is, to get the same income in the case, the residents near the facility bear the cost of construction of the facilities. With the increasing awareness of people's environmental protection, the broad masses of people are increasingly opposed to the construction of pollution-related NIMBY facilities, leading to a series of social group events, such as "anti-burning movement", "anti-PX movement", known as "NIMBY conflict". To ease the conflict, we need to give full play to stakeholders, including residents, experts, enterprises and environmental NGOs to achieve democracy and scientific decision-making. In the various stakeholders, the role of environmental NGO can not be underestimated.

In the decision-making of pollution-related NIMBY facilities, scholars have enough research on residents' complex, experts' trust, corporates' social responsibility and so on, and there is still room for the role of environmental NGO in decision-making of NIMBY facilities. The existing research is based on the case of an environmental NGO's activities to analyze its advantages and shortcomings. Such as Tong's" mobilization structure and the development of the natural conservation movement-take Nujiang anti-dam movement as an example"[2], in this article, the author took Nujiang anti-dam movement as an example, to explore the motive mechanism of nature conservation movement. Another example is Zhang's" environmental NGO's political opportunity to create space-take C City Environmental Protection Association on the government's action strategy as an example"[3],the author analyzed the behavior strategy C City's Environmental 
Protection Association taken to the government, and reached a conclusion that "Environmental protection NGO has been able to take both cooperative and supervised action strategy, that is because its core members' amphibious identity achieves the political participation and social participation both ". It can be seen that most of the existing research is based on specific cases and the conclusions are not universal. This paper attempts to analyze the role of environmental NGOs in the decision-making of pollution-related NIMBY facilities, and draw the basic path model of environmental NGO participation in decision-making of NIMBY facilities, providing ideas for the full play of environmental NGOs' role in decision-making of NIMBY facilities.

\section{The Necessity of Environmental NGO Participation in Decision-making of Pollution-related NIMBY Facilities}

Multi-center Governance Requirements. Multi-center governance theory is mainly embodied in the proposition of subject: governance includes both the government, but not limited to the government's set of social public institutions and actors[4]. This means that the power center includes local, regional, national and supranational and other diverse subjects. Other groups and individuals have played a positive role in public service supply and policy decisions. From the perspective of the relationship between the main body, any single organization can not solve all the problems alone, so we need to establish the public sector, the private sector and NGO triangle, and form the government, NGO and private sector collaboration network, to jointly solve the public business affairs.

In the governance of pollution-related NIMBY conflict, we should not only play the leading role of the government, but also strengthen the use of non-power group to focus on conflict resolution, so that the use of environmental NGO to resolve conflicts become the meaning of the title. Multi-center governance also requires that in the local social life, there are a variety of forces, including the autonomy and self-management of NGO and citizens. In solving social problems, unlike previous government administrations, there is a redistribution of action boundaries and responsibilities, and we put more emphasis on their interplay and coordination where the power dependence between the various social institutions and organizations involves in collective action.

Decision-making Interests. The concept of Stakeholder was originally used by the firm, proposed by the Stanford Research Institute. The main point of stakeholder theory is that stakeholders includes key stakeholders, secondary stakeholders and potential stakeholders basing on their different degrees on interest. A key stakeholder is a group of organizations or individual with high legitimacy whose own interests are closely related to the policy. They are the direct relies of policy implementation and their interest needs should be adequately considered in decision making. Secondary stakeholders are mainly groups of organizations and individuals who have little to do with the decision-making of NIMBY facilities. Since their own interests are largely unaffected by policies, they are less interested in the policy of facility construction. Potential stakeholders refer to organizations or individuals that take advantage of legitimacy, and different degrees of influence, legitimacy, and profitability have different combinations and manifestations among these types of stakeholders.

In the pollution-related NIMBY facilities decision-making, the potential stakeholders are those who occupy the legitimacy of the organization or individual, and the most typical is the environmental NGO. They are with a high degree of influence, because their professional quality and orderly organization are received and agreed by the majority of the public. Therefore, in the pollution-related NIMBY facilities decision-making process, we should give full play to the positive role of environmental NGOs.

Alleviate Public Sentiment and Correct Public Bias. Public awareness of the risk of pollution-related facilities is prone to bias. Pollution-related NIMBY facilities, especially nuclear energy facilities, the risk lies in its uncertainty, what harm will be caused before and after the construction, how much harm occurs, and whether these hazards are controllable, these are all uncertain. Scientists can not count and calculate these uncertain problems, and thus can not draw convincing conclusions given by the experiment. The public lack relevant scientific knowledge, so 
that scientists' fuzzy response on relevant issues will lead to public exaggeration or even imagination on the negative impact of pollution-related NIMBY facilities. Considering the uncontrollable harm to the physical and mental health of residents, they may take the anti-behavior to hinder the construction of adjacent facilities. Environmental NGOs play an important role in popularizing the public's scientific knowledge and alleviating public sentiment.

In addition, the public has a cognitive bias in the decision-making of pollution-related NIMBY facilities. Public short-sightedness ("myopia bias") makes them think that avoiding recent health losses is more important than long-term social benefits, resulting in a conflict with NIMBY facilities. At the same time, due to the information asymmetry between the public and the decision maker, the public receives incomplete or misleading information, feels that they are treated unfairly, and increasingly mistrusts the experts and government. Public awareness of prejudice requires environmental NGOs to be resolved through the diffusion of knowledge and struggle for the right to public participation.

\section{The Role of Environmental NGOs in The Decision-making of Pollution-related NIMBY Facilities}

Environmental NGO has the legitimacy and professional advantages in pollution decision-making. Environmental NGO is one of the earliest and most mature non-governmental organizations in the various types of nonprofit organizations in our country. The role of environmental NGOs in the decision-making process of pollution-related NIMBY facilities is mainly reflected in the following three aspects:

First, promoting environmental protection and improving the environmental awareness of citizens. According to the 2005 China Public Environmental Protection Index report, more than 60\% of the Chinese public thought that the current environmental protection propaganda is not enough. Environmental NGO has made a useful addition to the government's lack of capacity. Environmental NGOs and environmental protection volunteers use environmental protection activities, publishing books, distributing publicity materials, organizing lectures and training, new media and other channels to disseminate environmental protection concepts to society and the public, and to improve the awareness of environmental protection and environment consciousness. More than $50 \%$ of the environmental NGO also disseminate the public knowledge of environmental protection through their website. Environmental NGO promotes the formation of social shared values for environmental protection and encourages the public to pursue environmental benefits.

Second, safeguarding the public's environmental rights and interests. Environmental NGO can play an active role in safeguarding the public's en vironmental rights and protecting citizens' right to know, to participate and to supervise. In the first half of 2004, the work of the "Green River Basin", "Green Home" and "Friends of Nature", drew government' attention of the construction of the Nu River. Premier Wen Jiabao submitted to the State Development and Reform Commission's reporting, and pointed out that "it should be careful studied and reach a scientific decision-making. "

Third, participating in government public decision-making. With the growing maturity of environmental NGOs, they have evolved from simple activities to active participation in the formulation of public policies on the environment, and participation in hearings and symposiums at all levels. In September 2004, the State Environmental Protection Administration held a hearing on the construction of the anti-seepage project at the bottom of the Yuanmingyuan Lake. The representatives of "Friends of Nature", "Earth Throughout" and "Global Village" and other environmental organizations spoke at the hearing and made strong recommendations, which had a great help. In addition, environmental protection NGOs are also playing an active role in protecting endangered animals and developing green economy.

At present, China's number of environmental NGO registration is small, and the domestic law on the protection and support of the development of environmental protection NGO is not yet sound, so there are many difficulties of environmental NGOs in raising funds, recruiting volunteers, and absorbing social management personnel, so that the influence to decision-making is limited. 


\section{Path Analysis of Environmental NGO's Participation in Decision-making of Pollution - related NIMBY Facilities}

The Four Stages of Decision-making of Pollution-related NIMBY Facilities. According to american sociologist Simon's proposing of four-stage theory in decision-making process, this paper divides the pollution-related NIMBY facilities decision-making process into four stages: start-up stage, multi-programing stage, decision-making stage, and implementation stage.

The start-up stage is the beginning of the decision-making of pollution-related facilities, and the main task is to publicize the decision-making intention of the government and other decision-making related information. The multi-programing stage requires extensive comments, giving full consideration to the facilities decision-making requirements and public rights to form lots of building plans. Decision-making stage needs a variety of plans to compare and merit, and then the government approves and gives it legal norms. Implementation stage includes releasing plan, assessment plan and modificating plan.

Path Analysis of Environmental NGO 's Participation. From the four stages in decision-making of pollution-related NIMBY facilities, we find that each stage requires the full participation and role of environmental NGO.

In order to ensure the validity and authenticity of the information in the start-up stage, the environmental NGO uses the brochure, the official network, etc. to publish the information. Free access to detailed information of pollution-related NIMBY facilities is provided by the Internet, and other written materials about the facilities such as brochures are also disseminated. Environmental NGO news releasing ensures the correctness of decision-making messages, and avoids public sentiment caused by the external false information and error recognition, helping to promote consensus and achieve efficient decision-making.

At the stage of multi-programing, environmental NGO collects public opinions through public forums, public opinion surveys, and in-depth interviews (especially vulnerable groups). Environmental NGOs record public questions and suggestions through questionnaires and interviews to answer public concerns. Environmental NGO focuses on visiting groups that experts survey can not reach, especially vulnerable groups, listening to the views of low-income groups, women, the elderly and other vulnerable groups about NIMBY facilities. After that, environmental NGOs expresses their attitudes and requirements on the site selection, implementation, decision-making, demolition and nuisance of pollution-related facilities through public forums.

In the decision-making stage, environmental NGO uses hearings, voting and other specific ways to express their views. Environmental monitoring situation, emission indicator information, and environmental assessment report of the pollution-related NIMBY facilities are all publiced in the hearings, and environmental NGO expresses constructive comments on various programs and votes to merit. Environmental NGO represents the interests of the organization and the public.

During the implementation stage, environmental NGO participates in assessing the environmental impact and making reasonable changes of plans. At the same time, environmental NGOs collect public opinions through the network consultation, questionnaires, network platform, telephone counseling channels, and other means, to ensure that the public can express their rights and interests, and share their views on amending the plan.

In order to give full play to the participation of environmental NGOs in the decision-making of pollution-related NIMBY facilities, we should improve the legal protection mechanism of environmental NGO participation in such decision-making process. The sound legal system is an important guarantee for environmental NGO to participate. It is very necessary for our government to revise and formulate relevant laws and regulations, clearly stipulating the legal subject status, rights and obligations of Chinese environmental NGOs to participate in the management of public affairs, and making clear the definition of environmental NGO participation and participation areas. In addition, environmental NGO and government information sharing mechanisms should be established. The collection and disclosure of information are very important in the decision-making process of NIMBY facilities. Many of the NIMBY conflicts are generated and intensified by the fact that the government departments have concealed, falsed, and missed some information on the 
facilities. Under the information sharing mechanism, the relevant information is fully integrated, and the environmental NGO can communicate with the government in a timely and effective manner.

\section{Conclusion}

This paper analyzes the necessity of environmental NGO participation in the decision-making process of pollution-related NIMBY facilities from the perspective of stakeholders, summarizes the environmental NGOs' role in promoting the concept of environmental protection, safeguarding public rights and promoting public decision-making, and establishes the universal model of environmental NGO participation in various stages of pollution-related NIMBY facilities decision-making.

Today, the development of urban and urbanization urges the improvement of public facilities services. In recent years, opposition to the construction of pollution-related facilities is growing, leading to a series of group incidents such as anti-burning movement, so the role of environmental NGO in pollution-related facilities decision-making process is also growing. In order to give full play to the participation of environmental NGOs in the decision-making process of pollution-related facilities, the government should improve the legal protection mechanism of environmental NGO participation in such decision-making process and establish the information sharing mechanism between environmental NGO and government. With the development of public facilities, the type of NIMBY facilities is increasing, so the role of environmental NGOs in other types of NIMBY facilities is also worth studying.

\section{References}

[1] Yunqing Wu, Guofang Zhai, Shasha Li.Research Progress of NIMBY Facilities at Home and Abroad[J].Human Geography,2012(6):7-12

[2] Zhifeng Tong. Mobilization Structure and the Development of the Natural Conservation Movement-take Nujiang Anti-dam Movement as an Example[J].Open Age,2009(09):116-132

[3] Hubiao Zhang. environmental NGO's political opportunity to create space-take C City Environmental Protection Association on the government's action strategy as an example[J].Journal of Nanjing University of Technology,2013(04):112-119

[4] Gongrong Tan. Western Public Administration Thought and Schools[M].Peking: Peking University Press, 2008

[5] Le Zhang,Xing Tong. Decision-making Dilemma in Conflict Management of "NIMBY" and Its Solution[J].China Administration,2014(04):109-113

[6] Simon Feldman, Derek Turner. Why Not NIMBY[J]. Ethics Policy \&Environment,2014(17): $105-115$

[7] Yvonne Rydin, Maria Leet ,Simon J Lock. Public Engagement in Decision-Making on Major Wind Energy Projects[J]. Journal of Environmental Law,2015(3):1-12

[8] Anna Drazkiewicz,Edward Challies,Jens Newig.Public participation and local environmental planning:Testing factors influencing decision quality and implementation in four case studies from Germany[J]. Land Use Policy,2015,2(46):211-222

[9] Thomas C.Using Social Goals to Evaluate Public Participation[J].Policy Studies Review,1999,16(3):75-103

[10] Michael E Kraft,Bruce B Clary.Citizen Participation the NIMBY Syndrome:Public Response To Radioactive Waste Disposal[J].The Western Political Quarterly,1991,2(44):299-328 